\title{
Los Podcast como forma significativa de reinterpretar los conceptos en los procesos de lectoescritura desde los ambientes virtuales de aprendizaje
}

\author{
Jaime Oswaldo Linares Guerra ${ }^{1}$ \\ Carlos Augusto Corredor Ramírez ${ }^{2}$
}

Recibido: 18 de febrero de 2015 - Aceptado: 9 de mayo de 2015

\section{Resumen}

La Universidad Santo Tomás, con el objeto de utilizar las nuevas tecnologías, está interesada en usar de forma audaz recursos como el Podcast en tareas elementales que facilitan el proceso de enseñanzaaprendizaje. En un inicio se propone la asignatura de Lectoescritura, en la cual es vital tener en cuenta definiciones tales como las categorías gramaticales, la estructura morfosintáctica, conectores, etc., que son de una relevante importancia en el momento de aprender a elaborar escritos con coherencia y cohesión.

Palabras clave: podcast, lectura, escritura, ambiente virtual, aprendizaje

\section{El ejercicio de leer y escribir en la educación superior}

Escribir y leer son dos procesos fundamentales del ser humano; somos partícipes de una cultura que interpreta los signos y símbolos. El hombre procura entender el sentido de su realidad y logra plasmar dicho entendimiento por medio de la expresión oral y escrita, de ahí que leer y escribir sea para toda persona una forma de interpretar su contexto.

Si nos detenemos un poco en las etapas escolares de un estudiante colombiano, es posible encontrar que a temprana edad tenga gusto por la lectura, que sus primeras letras estén acorde a la simetría y armonía en la construcción de una frase, oración o texto; pero, hoy en el siglo XXI, es primordial no dejar de lado la enseñanza y descubrir nuevas herramientas que logren captar la atención de los niños en sus búsqueda por el aprendizaje de la lectura y la escritura.

Según Vázquez (2008), la lectura refuerza y revitaliza la escritura, pues el ejercicio diario de leer fortalece el proceso de escritura, ya que al adentrarnos a un proceso de inferencia y comprensión hace posible descubrir por medio de la recreación otros modos de pensar.

La lectura y la escritura en los niños se presenta de manera similar, como en el inicio o aparición de los primeros hombres: es importante señalar

1. Docente de Tiempo completo perteneciente a la Universidad Santo Tomás, Licenciado en Filosofía y Letras con Magister en filosofía latinoamericana. Correo: jaimelinares@usantotomas.edu.co 
el dibujo, pues representa el valor iconográfico de una sociedad, donde registra su mundo cotidiano, fija el tiempo y la memoria de lo sucedido. En una pared o cerámica (colocar nota a pie de página las cuevas de Altamira, espejo enterrado y jarrones griegos), la experimentación de los sonidos, pues se procura imitar aquellos elementos dela naturaleza llevados a la danza y la música y, por último, los gestos que manifiestan las emociones del ser humano. Todo este acontecer se encuentra involucrado en el proceso de lectoescritura, pues los niños a temprana edad dibujan o rayan las paredes, imitan el sonido de los animales y sus gestos son la reacción de sus emociones.

Además, es preciso señalar que el proceso educativo dura toda la vida, y el acto de leer y escribir es perenne al ser humano, aunque se diferencia por la situación y contexto donde viven los niños en los primeros años de vida. Además, no es lo mismo nacer en aquel lugar donde la tecnología es preponderante e imponente a los cambios y necesidades de esa sociedad del conocimiento, a otro espacio donde son precarias las condiciones para el desarrollo o adquisición de la información. Todos enseñamos y todos aprendemos en el transcurso de nuestra existencia, se aprende a leer e interpretar el mundo lleno de imágenes y símbolos, pero de igual manera se aprende a escribir y plasmar aquello que nos rodea por medio de la metáfora o lo mágico.

Ahora bien, en la adolescencia parece cambiar la situación, pues el niño que prestaba atención a un libro o narración, transforma su rol por nuevos escenarios que encuentra en su contexto: televisión, tableta, celular, redes sociales, que lo atraen, pero no lo involucran de manera profunda en el conocimiento. Se puede decir que existen falencias, pero la mejor forma de encontrar la empatía entre el mundo de la lectura y escritura es en la creación y desarrollo de ambientes de aprendizaje.

Una imagen vale más que mil palabras, puede ser el eslogan en la sociedad que vivimos, pues los niños y jóvenes encuentran en los medios de comunicación un manejo de la información diferente a la que vivieron otros estudiantes hace un par de décadas, el modo de leer de los estudiantes de esta nueva época se dirige a unos conocimientos básicos suministrados por los medios de comunicación, sin embargo, debe existir una orientación para llegar a la unificación del conocimiento. Se lee e interpreta el mundo, se piensa y se escribe en ideas lo que reflexionamos sobre el mundo que habitamos.

Sin embargo, para nuestros jóvenes, se escribe y se lee de manera diferente en el mundo, dado que la labor del docente y la entidad educativa tiene como objeto contribuir en la construcción de conocimiento por medio de una didáctica y pedagogía de la imagen.

De esta manera, en los colegios y las escuelas se construyen estrategias de lectura y escritura, pero teniendo como fondo un ambiente virtual de aprendizaje, tales como blogs de asignaturas, la utilización de la plataforma Moddle, las web interactivas, la utilización de redes sociales todas con un fin u objetivo desarrollar habilidades y competencias para el fomento y la interacción de la lectura y la escritura en la educación secundaria.

Hoy nuestros jóvenes que asisten en el aula son internautas que, día a día, aprenden con la Red, que navegan en mundos virtuales para alcanzar nuevos conocimientos o saberes, diferentes a la exposición del maestro. Señalemos un ejemplo de lo anteriormente mencionado, con el video juego Dantes Inferno, que, de una u otra manera, ambienta el escenario dantesco con un universo de imágenes tridimensionales que impactan la visión del espectador, juego que sería oportuno como herramienta de acceso a la temática Literatura Universal en la obra del magno Dante Alighieri y su obra maestra La Divina Comedia.

De manera que estos juegos interactivos no muestran desidia hacia el estudio, sino que colaboran en imaginar esos mundos posibles que los jóvenes desean recrear en sus mentes, 
por lo tanto, el docente en vez de ser un agente reiterativo de conceptos, datos y autores de la literatura clásica, se debe convertir en un maestro propositivo acorde a las nuevas tecnologías, propiciando una didáctica entre lo virtual y el texto literario.

En el ambiente universitario, el primer semestre es aquel tiempo de introducción a distintas asignaturas teniendo como referente la disciplina o carrera a estudiar, los jóvenes entran a su primer día de clase con expectativas de su profesión, escenario académico y la forma de evaluación.

La Universidad Santo Tomás en los últimos años ha brindado cursos de lectura y escritura en educación superior para los estudiantes que ingresan por primera vez a la institución universitaria. Este proyecto comienza en el año 2005 bajo la dirección del Departamento de Humanidades y Formación Integral, en el año 2006 se fomenta la línea de investigación Fray Luis de Granada (estudios del lenguaje) donde se ha venido desarrollando el trabajo de los cursos de nivelación de lectoescritura en cuanto a la producción oral y escrita como características inherentes al campo universitario.

Ahora bien, la Universidad Santo Tomás no solo ha brindado estos espacios frente al trabajo de comprensión de lectura y producción de textos de manera presencial sino que además cuenta con la participación de los cursos en modalidad a distancia que ofrece la VUAD, para el año 2012 se implementó un curso de habilidades comunicativas, proyecto liderado por el Departamento de Bienestar y Facultad de Ciencias y Tecnologías donde se diseñaron aulas virtuales, material didáctico, instrumentos de evaluación y objetos virtuales de aprendizaje (OVA).

Para el año 2013, bajo de la dirección de Fray Alberto René Téllez y la coordinadora de lectoescritura Clara Inés Jaramillo, se da inicio a la conformación de cursos neotomasinos en lectoescritura, donde se capacitan a un número de docentes frente a la nueva estrategia de enseñanza-aprendizaje de leer y escribir en la educación superior, donde se unifican criterios académicos y de evaluación que posteriormente serán base de insumo para las facultades y la UDIES.

Así mismo, en el año 2014 y en el marco del proyecto USTA Colombia, espacio en el cual el propósito de la Universidad es integrar las actividades de forma integral, las cuales deben replicarsen en cada una de las sedes y seccionales, se ha venido trabajando con las distintas sedes en los cursos de inducción a neotomasinos en lectoescritura, al igual que la capacitación a los docentes que integran los multicampus.

Por todo lo anterior, la Universidad Santo Tomás, desde el Departamento de Humanidades y Formación Integral, asume como tarea seguir afianzando los procesos de enseñanza y aprendizaje de la lengua materna, ya que todo profesional, sea cual sea el campo de acción en que se desempeñe, debe poseer habilidades de lectoescritura que le permitan perfilarse integralmente en su entorno laboral. Por ello, a los estudiantes se les prepara para: a) la comunicación de ámbito social y laboral: exponer ante grupos numerosos, entrevistas, presentar pruebas orales, participar en los medios de comunicación, dialogar en la vida cotidiana, b) las nuevas tecnologías: teléfono, radio y televisión, y c) las situaciones académicas: entrevistas, exámenes orales, exposiciones.

Para ello, los cursos de lectoescritura están encaminados a desarrollar las competencias de escritura y comprensión lectora a través del trabajo continuo y personalizado, para que el estudiante identifique sus falencias y paulatinamente las vaya superando, aplicando las herramientas pertinentes para la construcción de un texto coherente y de calidad; igualmente se pretende que éste comprenda e interprete con pensamiento crítico los textos y desarrolle unos procesos y hábitos de estudio. 


\section{Habilidades comunicativas}

En uno de sus artículos Francisco Cajiao (2005) argumenta "En el mundo de hoy siempre se está leyendo desde que se despierta en la mañana hasta que se vuelve a dormir" (36) esta frase del autor del libro Instrumentos para escribir el mundo refleja bastante lo que significa hoy la lectura para nuestros jóvenes, se lee y se interpreta de manera constante en el día a día, ya no son solo palabras las que debemos comprender para luego inferir una idea, sino que hoy en el siglo XXI la publicidad, los vídeos musicales las redes sociales entre otros nos hacen participe de un conglomerado de imágenes y símbolos que debemos interpretar.

Por otro lado, las estrategias de aprendizaje que busca el curso de lecto escritura a neotomasinos es la de una formación crítica, donde cada texto sea dinamizador de ideas, indagaciones, cuestionamientos que respondan a las problemáticas particulares y la realidad sociopolítica y cultural del mundo contemporáneo, es decir que no solamente nos detenemos en la gramática, la producción textual y la lectura crítica sino que además buscamos una formación integral. Según Vidal (2012) la USTA ofrece una formación integral donde el estudiante tiene un compromiso con el mundo y su nación, siendo responsable de sus acciones como persona y profesional.

El trabajo argumentativo es otro de los componentes del curso ya mencionado, por medio de la argumentación se propende a que todo estudiante sea productor y generador de ideas, teniendo como respaldo su opinión, su punto vista que de manera oral o escrita converge en la organización y construcción de sus expresiones. Y por último una función propositiva donde maestro y estudiante participan de manera colectiva y dinámica en la producción de conocimiento, donde la interacción sea eje fundamental fortaleciendo las competencias comunicativas e investigativas.

Por lo tanto, el trabajo de lectoescritura está orientado por los principios básicos del constructivismo que pueden sintetizarse así: a) el conocimiento se construye a partir de la acción, pero no se trata simplemente de la acción como recurso didáctico (mantener al estudiante activo), para que no se distraiga, sino que se concibe la acción como la posibilidad que tiene el sujeto de interactuar consigo mismo, con los objetos del mundo y su ambiente natural y socio- cultural para analizar y construir el conocimiento, b) el nuevo conocimiento es condicionado por el saber previo, pero éste a su vez reestructura ese saber y c) el papel del docente no es el de simple transmisor de conocimientos: va más allá. Es la persona que aplica su saber pedagógico para facilitar, orientar, motivar y colaborar en el proceso de aprendizaje.

\section{La importancia de los Podcast en la formación superior como alternativa para diseñar ambientes virtuales de aprendizaje}

A través de los años, las formas de permitir la reflexión significativa de los contenidos en las asignaturas han sido diversas y buscan que el estudiante pueda reconocer los fenómenos tratados, interpretar su origen y poder hacer diferentes ejemplificaciones sobre esas temáticas tratadas. Desde los elementos mnemotécnicos tan elementales como fichas bibliográficas, carteleras, frisos, y folletos, los cuales tenían por objeto representar que se entiende de lo que se lee y que productos se pueden generar a partir de los recursos que se tenían a la mano.

Finalizando la década de los noventa, surgen nuevos elementos que permitieron fortalecer el manejo de contenidos, entre ellos surgió Encarta (Microsoft), la cual buscaba por medio de textos breves basados en definiciones, llevar al estudiante a vivificar y resaltar con mayor nivel actualización, cada uno de los conceptos, fenómenos y hechos históricos que le permitían formarse. Este elemento con el tiempo fue integrando nuevos recursos interactivos tales como gifs, sonidos, mapas, y galerías que le facilitaban al educando un nivel de acercamiento con cada uno de los elementos allí alojados. Este proceso de ir al documento enciclopédico tiene 
una vital importancia para el desarrollo de las pedagogías, en tanto que no solo presentaron un nuevo acceso a la información, también incursionaron en la internet, lo que llevó a explorar el ciberespacio y su vital relevancia en todos los horizontes; tal es la importancia de este contexto que Pierre Levy lo define así:

Para guiar la construcción del ciberespacio, para ayudar a seleccionar entre las diferentes orientaciones posibles, incluso para imaginar nuevas, proponemos un criterio de selección eticopolítico, una visión organizadora./Los dispositivos que contribuyen a la producción de una inteligencia o de una imaginación colectiva deberían ser fomentados. Según este principio general, se deberá estimular preferentemente:/ 1. Los instrumentos que favorecen el desarrollo del vínculo social por el aprendizaje y el intercambio de conocimientos. /2. Los métodos de comunicación aptos para escuchar para integrar y restituir la diversidad más bien que los que reproducen la difusión mediática tradicional. /3. Los sistemas que tienden al surgimiento de seres autónomos, cualquiera que sea la naturaleza de los sistemas (pedagógicos, artísticos, etcétera) y seres (individuos, grupos humanos, obras, seres artificiales) (Levy, 2001, p74).

Este análisis expone cual es el papel del individuo frente a este recurso que surge de acuerdo a las nuevas estrategias globalizantes que imponen una serie de innovaciones a nivel tecnológico. El uso de aplicaciones como Power Point, Visio, Excel, Paint, y Publisher, fueron recursos de vital importancia para abreviar procesos y permitirle al estudiante reemplazar aquellas actividades que podían estar comparadas con ejercicio lúdico, el cual instauraba una igualdad al realizar tareas.

En la actualidad, las páginas de las grandes universidades del mundo ofrecen diversas alternativas de formación virtual a sus estudiantes.
Entre ellas existen plataformas como Moodle y Blackboard, en las cuales se organizan una serie de contenidos que presentan ideas, reflexiones y ejercicios que garanticen la interacción entre el docente y el estudiante. Entre las herramientas más empleadas en estos espacios son, tareas, test, wikis y foros. Cada una de ellas permite vislumbrar los alcances interpretativos que cada una de ella sugiere, entre hacer lectura de pdf, textos en Word y mapas conceptuales, hasta los mismos videos que algunas facultades emplean para complementar los ejercicios de aprendizaje. Desde la implementación de los formatos .exe, ellos permitieron dinamizar la lectura y la ejemplificación de cada uno de los temas y conceptos abordados.

Sin embargo desde la llegada de nuevos recursos tecnológicos que acercaron una serie de aplicaciones novedosas tales como Prezi, Powtoon, Pixton, Blubbr, entre otras, que intentan cada vez ampliar el grado de significación de los contenidos en los campos del aprendizaje. Prezi, es un recurso expositivo de origen Húngaro, que tiene como finalidad aumentarle a las presentaciones conceptuales una serie de manejos de la imagen, rotaciones, secuencias, uso de gifs e imágenes tridimensionales que posibilitan que el usuario sea más creativo en el momento de exponer sus ideas y reflexiones. Su versatilidad para emplearla permite desde visualizar los contenidos online, insertarla desde un código html en blogs y correos, hasta poder descargarla a una Usb y poder visualizarla sin tener que estar conectado a la red.

Blubbr y Pixton permiten crear cuestionarios online y compartirlos a través de diferentes medios de la red, crear historietas que posibiliten obtener la interpretación de un estudiante por medio de un relato y a su vez hacer reflexión sobre el mismo y socializarla. Al hacer el proceso de inscripción en la aplicación, este recurso puede compartir los productos generados con las redes sociales más comunes como Facebook, Twitter, Instagram, entre otras que 
hacen que este material pueda llegar a muchos usuarios y hacer comentarios frente a lo que se observa.

En cuanto al Podcast, a diferencia de estas alternativas expositivas tiene varios propósitos, entre ellos y el más reconocido son los tutoriales, los cuales permiten orientar mediante una serie de parámetros desde cómo hacer una acción tan elemental como instalar un software en nuestro computador, hasta hacer una simulación sobre un juego de consola. Es tan amplio el margen de los Podcast que permiten integrarse a diferentes dinámicas. Aquellos estudiantes que por motivos de fuerza mayor deben aplazar sus estudios ven en esta herramienta una forma de reforzar aquellos conocimientos que a la fecha poseen.

En el campo de la ciencia, los podcast tienen una función fundamental, pues ellos pueden permitir la simulación de situaciones y poder contrastarlas con las teorías. De la misma manera en campos como la literatura o la filosofía, esta herramienta cumple un papel representativo en cuanto a la descripción que se hace de los autores, como la mención de los movimientos narrativos o aquellos que estructuraron el pensamiento. Apple y Android ofrecen en sus tiendas virtuales de forma gratuita Podcast de diferentes ciencias que se convierten en una herramienta que se puede llevar a cualquier contexto, de manera portable y su diseño facilita que pueda alojarse una buena cantidad de información en diferentes formatos con el fin de mantener de forma vitalicia estas ideas.

\subsection{Características de un Podcast}

Este elemento tiende a poseer varios campos de acción:

1. Tutorial: en este aspecto el Podcast posee la facilidad de orientar al usuario en procesos que requieren una secuencia estricta para ser llevados a cabo.

2. Audio ayudas: son pistas en diferentes formatos (mp3, mp4, wma) en los cuales sirven para que el estudiante pueda reproducir estos elementos de forma online y descargarlos a su ordenador o Smartphone y emplearlos según sus necesidades.
3. Simuladores: son videos que tienen como función reproducir situaciones, experimentos que permitan aclarar acciones que de alguna manera requieran de observaciones paso a paso y acercamientos.

4. Relatos: son apreciaciones que se hacen sobre material narrativo y que tienen como fin complementar la información que se recoge de la academia y que de esta manera le permite al estudiante reconocer cada uno de los aspectos tratados y poder exponer con fluidez cada una de las temáticas que sean de interés.

5. Mnemotécnia: Es una pista de audio grabada por un especialista en el tema, con el fin de explicar conceptos y trabajar elementos de pronunciación de palabras en el caso del aprendizaje de competencias lectoras y dominio de lengua extranjera.

En este último numeral se quiere hacer énfasis, pues en el espacio académico que posee la Universidad Santo Tomás, denominado Nivelación de Competencias en Lecto Escritura, busca complementar los recursos desde los cuales se brinda un contenido en Scorm, el cual es de fácil acceso a la lectura, pero con el auge de los Smartphone $\mathrm{y}$ tablets se hace vital que los estudiantes matriculados en este espacio académico posean esta ayuda que les permite recordar y contextualizar los saberes que se expresan en el aula. Actualmente la Universidad Santo Tomás viene desarrollando una serie de cursos (Espacios de extensión, Diplomados, etc), en los cuales se pone en práctica este tipo de dinámicas, las cuales tienen por objeto actualizar al personal docente desde temáticas como pedagogía, idiomas, estrategias de aprendizaje, lectoescritura, y matemáticas.

Cada uno de estos módulos está diseñado con el fin que los estudiantes integren estas estructuras metodológicas digitales en sus espacios de formación de pregrado y posgrado; a lo anterior se acopian no solo saberes y procedimientos, también se adaptan a una nueva forma de enseñanza la cual integra recursos cooperativos tales como foros, wikis, test compartidos por 
medio de la red tales como los generados desde la plataforma Blubbr, presentaciones significativas desde Emaze, Prezi, Poowtoon y Mindomo. Sí se emplean este tipo de aplicaciones en contextos académicos se pueden volver recursos dinámicos en los cuales se pueden socializar diferentes tipos de contenidos y hacer de ellos objeto de nuevas reflexiones que hace que cada uno de estos cursos potencie la forma de compartir conocimiento remotamente.

\section{Referencias textuales}

1. Cajiao, F. (2005). Instrumentos para escribir el mundo: escritura, lectura y política. Bogotá: Editorial Magisterio.

2. Levy, P. (2001). Inteligencia colectiva, Oms, Recuperado desde: http://inteligenciacolectiva.bvsalud.org/public/ documents/pdf/es/inteligenciaColectiva.pdf

3. Ospina, W. (2007). La ciudad de los libros. Ponencia magistral. Recuperado desde: http://www.fundacionblu.org/ actaslengua/subir/ConferenciamagistralWillianOspina.pdf

4. Vásquez, F. (2008). La escritura y su utilidad en la docencia. Revista actualidades pedagógicas No 51 Recuperado desde: http://revistas.lasalle.edu.co/index.php/ ap/article/viewFile/1354/1238

5. Vidal, M. (2012). Pautas para la fundamentación humanística e investigativa de los trabajos de grado e informes finales de pasantía en la Universidad Santo Tomás. Bogotá. 